\title{
Prevention of Worsening of Drug Abuse in Soldiers
}

\author{
Ali Reza Karambakhsh, ${ }^{1}$ Ali Reza Mehrazmay, ${ }^{1}$ Zahra Najafimanesh, ${ }^{2}$ Mahmood Salesi, ${ }^{1}$ and \\ Khodabakhsh Ahmadi ${ }^{*}$ \\ ${ }^{1}$ Behavioral Sciences Research Center, Baqiyatallah University of Medical Sciences, Tehran, IR Iran \\ ${ }^{2}$ Department of Clinical Psychology, Kharazmi University, Tehran, IR Iran \\ "Corresponding author: Khodabakhsh Ahmadi, Behavioral Sciences Research Center, Baqiyatallah University of Medical Sciences, Tehran, IR Iran. Tel: +98-2182482475, Fax: \\ +98-2188053767, E-mail: kh_ahmady@yahoo.com
}

Received 2014 November 16; Revised 2015 April 14; Accepted 2015 April 20.

\begin{abstract}
Background: Military service is one of the stressful life periods for young men in Iran, and because of these multiple stressors, soldiers' drug abuse status can be exacerbated during this period. Identifying the predictors of worsening drug abuse can help us to control addiction in young soldiers.

Objectives: To examine the military service predictors resulting in worsening drug abuse status.

Patients and Methods: A cross-sectional study with 3140 young soldiers was conducted in summer and autumn of 2010 and; the participants completed three questionnaires, namely the Texas Christian University Drug Screen (TCUDS) II, The Addiction Severity Index and a questionnaire designed by the researchers. We analyzed the data using ordinal logistic regression. The dependent variable was changing the drug abuse status, scored from 1 to 4 according to the state of deterioration of soldiers' drug abuse.

Results: The study included 3,140 soldiers with a mean age of 22.1 year. The predominant level of education among the soldiers was a diploma (72.6\%), and $87.7 \%$ of the soldiers were single. In the model, the four predictors that affected drug abuse status deterioration were as follows: level of satisfaction with service location (odds ratio $[\mathrm{OR}]=0.83, \mathrm{P}=0.040)$, relationship with commander $(\mathrm{OR}=$ $0.79, \mathrm{P}=0.001)$, relationships with other soldiers $(\mathrm{OR}=0.71, \mathrm{P}=0.031)$, and the time of additional service $(\mathrm{OR}=1.15, \mathrm{P}=0.002)$.

Conclusions: To prevent worsening drug abuse status among soldiers, it is necessary to decrease the time of additional service, increase the quality of the commander's relationship with soldiers, and elicit soldiers' help to assist decision makers in controlling the deterioration of soldiers' drug abuse during military service.
\end{abstract}

Keywords: Substance Abuse, Military Personnel, Military Facilities, Prevention

\section{Background}

The Islamic Republic of Iran (IR. Iran) is one of the countries in the drug trafficking route named the golden crescent (1), and this is a risk factor for drug abuse in this country. According to the last report of the Iran drug control headquarters (IDCH), the number of drug abusers is approximately $1,325,000$ persons, $45 \%$ of which are under 29 years old. The mean age at which drug abuse begins is 21 years old (2). Those who use intravenous drugs make up 9 to $16 \%$ of drug abusers (3).

Stress is a term that is frequently used in a variety of social, academic, and employment settings. Everyone needs a certain amount of pressure to elicit their best performance. However, when pressure exceeds a person's ability to cope, this results in stress (4). Stress is a well-known risk factor in the development of addiction and in addiction relapse vulnerability. A series of population-based and epidemiological studies have identified specific stressors and individual-level variables that are predictive of substance use and abuse (5).

In IR. Iran, most of the young men between 18 and 28 years old must complete military service, and this stressful period is one of the high-risk periods for initial or worsening drug abuse (6). Military service is associated with many stressors, such as being placed in a new environment, the hardships of military life, problems with the commander, failure to properly solve problems, and so on $(7,8)$.

Knowing about the military service predictors that affect addiction status can help decision makers to reduce their severity or eliminate the risk factors and control the deterioration of addiction status in soldiers.

\section{Objectives}

To find the military service predictors of worsening drug abuse in soldiers.

\section{Patients and Methods}

\subsection{Subjects}

This research is a cross-sectional study and data were taken from one of the military services where young sol-

Copyright (c) 2016, Zahedan University of Medical Sciences. This is an open-access article distributed under the terms of the Creative Commons Attribution-NonCommercial 4.0 International License (http://creativecommons.org/licenses/by-nc/4.0/) which permits copy and redistribute the material just in noncommercial usages, provided the original work is properly cited. 
diers lived in the summer and autumn of 2010. The participants were 3,140 soldiers with a mean age of 22.1 years. They responded to questions about the changing status of addiction in this military period.

\subsection{Procedure}

In this study, we attempted to select cases from the entire group of the soldiers that had lived in the garrison for at least 3 months of their service period. For Iranian young men, there is a mandatory military service period of 24 months. The soldiers who agreed to participate in this research were informed by the researcher that the survey was voluntary and the results would remain anonymous; the researcher then explained the questionnaires. We used three questionnaires, as follows:

1) The Texas Christian University Drug Screen (TCUDS) is self-administered and serves to quickly identify individuals with a history of heavy drug use or dependency (based on the DSM and the national institute of mental health NIMH diagnostic interview schedule); this tool was validated by Knight et al. (9);

2) The Addiction Severity Index (5th edition), validated by Makela (10), was used to introduce and explain the seven potential problem areas for soldiers: medical, employment/support status, alcohol, drug, legal, family/social, and psychiatric factors;

3) A Researcher-Designed Questionnaire asked about the respondents' demographic information and veteran status, including age, education level, marital status, job, and types and methods of abused substances. To validate this questionnaire, engage in deeper investigation of the variables in the target population and explore possible mentioned factors, we chose a sample of target population $(n=20)$ to participate in exploratory interviews with psychologists.

\subsection{Dependent and Independent Variables}

The dependent variable was changing of the status of drug abuse, with four options in the questionnaire, as follows: 1) beginning, 2) Decreasing, 3) Increasing, and 4) unchanged. We scored these options according to the state of deterioration of soldiers' drug abuse (Table 1); thus, the scores for these items were as follows: beginning $=4$, increasing $=3$, unchanged $=2$, and decreasing $=1$. The cases were divided in to four groups according to their scores (Table 1$)$.

We investigated the factors related to the military situation as the independent variables, including desertion rates during the period of military service, average drug abuse of friends in military service, time of additional service, satisfaction with service location, relationships with other soldiers, and relationships with commander. These variables were all scored from 1 to 5 .

\subsection{Analyses}

Data were analyzed using SPSS 21 . We used ordinal logistic regression to analyze the factors by the backward method; also, we used the chi-square and Fisher's exact tests to determine some factors related to the military predictors of deterioration of soldiers' drug abuse. In the results, we report three statistical components, as follows: the P value, odds ratio (OR), and standard error (SE). A P value under 0.05 was considered significant.

\section{Results}

\subsection{Descriptive Results}

The total number of participants was 3,140 soldiers with a mean age (95\% confidence interval [CI]) of 22.1 (21.6, 22.6) years old. The predominant level of education of the soldiers was a diploma (72.6\%). Details of the descriptive results are given in Table 1 .

The frequency effect of military service in the deterioration soldiers' drug abuse status was as follows: beginning $=67(2.1 \%)$, increasing $=84(2.7 \%)$, unchanged $=2911(92.7 \%)$, and decreasing $=78$ (2.5\%; Table 2$)$.

\subsection{Univariate Results}

Univariate analysis of military service independent variables in relation to change in soldier drug abuse status showed that some variables significantly worsened drug abuse status, such as the relationship with the commander, satisfaction with service location, loneliness in military service, and so on. These factors are listed in Table 3.

\subsection{Multivariate Results}

The results of final logistic model that explain the significant military predictors of drug abuse status are reported in Table 4.

In this model, we find that a higher level of satisfaction with service location is associated with higher odds of worsening soldier drug abuse status $(\mathrm{OR}=0.83, \mathrm{P}=0.04)$. Meanwhile, a better relationship with the commander has an inverse relationship with worsening soldier drug abuse status ( $\mathrm{OR}=0.79, \mathrm{P}=0.001)$, as does better relationships with other soldiers $(\mathrm{OR}=0.71, \mathrm{P}=0.031)$. Finally, we find that the risk of soldier drug abuse status increases with greater time of additional service $(\mathrm{OR}=1.15, \mathrm{P}=0.002)$. 
Table 1. Dependent Variable Definitions, Score, and Frequency ${ }^{a}$

\begin{tabular}{|c|c|c|c|}
\hline Parameters & Short Name & Score & Values \\
\hline Starting drug abuse during military service & Beginning & 4 & $67(2.1)$ \\
\hline Increasing drug abuse during military service & Increasing & 3 & $84(2.7)$ \\
\hline No change in drug abuse during military service & Unchanged & 2 & $2,911(92.7)$ \\
\hline Decreasing drug abuse during military service & Decreasing & 1 & $78(2.5)$ \\
\hline Total & & & $3,140(100)$ \\
\hline
\end{tabular}

${ }^{\mathrm{a}}$ Values are expressed as No. (\%).

Table 2. Demographic Information of Soldiers With Drug Abuse

\begin{tabular}{|c|c|}
\hline Variable & Values \\
\hline Age, mean (95\% CI),y & $22.1(21.6,22.6)$ \\
\hline \multicolumn{2}{|l|}{ Education } \\
\hline Diploma & 72.6 \\
\hline B.Sc & 25.6 \\
\hline Ph.D, MD & 2 \\
\hline \multicolumn{2}{|l|}{ Marital status } \\
\hline Single & 87.7 \\
\hline Married & 12.3 \\
\hline
\end{tabular}

Abbreviations: B.Sc., Bachelor of Science; M.Sc., Master of Science; Ph.D., Doctor of Philosophy; MD, Medical Doctor.

${ }^{a}$ Values are expressed as percentage unless otherwise indicated.

\section{Discussion}

We investigated many factors related with the period of military service, and ultimately identified four linked factors as the predictors of drug abuse in them. These factors were as follows: a) relationship with the commander, b) relationships with other soldiers, c) time of additional service, and d. level of satisfaction with the service location.

The relationship with the commander had an inverse relationship with worsening drug abuse. This may be because soldiers' stress increased when they had a bad relationship with commander; if they were unable to solve problems effectively (8), soldiers may have tended to abuse drugs as a tranquilizer to decrease stress.

In terms of relationships with the other soldiers, we found the same result as for the first factor. Our finding means that if soldiers did not have a good relationship with their peers, because of their high frequency of contact and the challenges this posed, their level of stress and discomfort increased.

The third predictor was time of additional service, which showed an inverse relationship with drug abuse.
This means that increased days of additional service as a disciplinary action can increase the odds of worsening drug abuse, perhaps because the psychological stress of this service leads them to cope through drug abuse.

The final predictor was the level of satisfaction with the service location, which had an inverse relation with worsening drug abuse. This finding showed that a lower level of satisfaction with service location can exacerbate the drug abuse status because this is an environmental stressor.

According to Sinha, stress is a well-known risk factor in the development of addiction and in addiction relapse vulnerability (5). This researcher also clarified that there is substantial literature on the significant association between acute and chronic stress and the motivation to abuse addictive substances (11). Moreover, Kaplan and Sadock reported that five factors are related with increasing opium compound abuse, including various crises (12); one of these crises arises from bad relationships with the commander and other soldiers. Lewis listed the predictors of drug abuse and stated that if the peripheral stress is higher than person's compatibility, the risk of drug abuse is increased (13). In our research, we can conclude that one 
Table 3. Univariate Analysis Result of Military Factors Related to Drug Abuse Change ${ }^{a}$

\begin{tabular}{|c|c|c|c|c|c|}
\hline Variable & Decreasing & Unchanged & Increasing & Beginning & P Value \\
\hline Remaining months of military service & $8.32 \pm 5.76$ & $8.04 \pm 4.48$ & $8.61 \pm 4.75$ & $8.73 \pm 5.09$ & 0.359 \\
\hline Time of additional service & $2.09 \pm 5.34$ & $1.59 \pm 3.06$ & $1.05 \pm 1.40$ & $1.12 \pm 3.73$ & 0.056 \\
\hline Average sentry duty time per week & $26.1 \pm 49.32$ & $23.03 \pm 36.39$ & $15.43 \pm 13.32$ & $20.16 \pm 87.26$ & 0.465 \\
\hline Daily average of leave for the month & $4.55 \pm 5.24$ & $5.75 \pm 16.22$ & $7.06 \pm 8.70$ & $3.8 \pm 6.48$ & 0.684 \\
\hline Average vacation hours per week & $8.61 \pm 16.84$ & $6.03 \pm 15.30$ & $9.90 \pm 13.29$ & $5.00 \pm 10.65$ & 0.702 \\
\hline Average nights in the barracks & $12.07 \pm 10.78$ & $11.04 \pm 11.58$ & $14.85 \pm 11.28$ & $11.77 \pm 11.53$ & 0.121 \\
\hline Absenteeism rate during the period of military service & $8.55 \pm 39.01$ & $4.99 \pm 19.60$ & $3.61 \pm 11.42$ & $1.59 \pm 13.12$ & 0.009 \\
\hline Desertion rate during the period of military service & $0.34 \pm 1.35$ & $0.25 \pm .86$ & $1.4 \pm 11.39$ & $0.29 \pm 9.20$ & 0.474 \\
\hline Encouragement in the course of military service & $3.42 \pm 12.39$ & $2.02 \pm 5.01$ & $2.1 \pm 3.44$ & $2.35 \pm 4.15$ & 0.284 \\
\hline Punishment of the period of military service & $17.18 \pm 122.96$ & $2.31 \pm 3.49$ & $1.75 \pm 4.50$ & $1.69 \pm 32.49$ & 0.031 \\
\hline Detainment during the period of military service & $0.75 \pm 2.02$ & $0.41 \pm .92$ & $0.76 \pm 2.58$ & $0.45 \pm 9.20$ & 0.957 \\
\hline Imprisonment during the period of military service & $0.36 \pm 1.90$ & $1.25 \pm 10.06$ & $0.28 \pm 1.41$ & $0.27 \pm 9.08$ & 0.564 \\
\hline Relationship with commander & $3.36 \pm 1.18$ & $3.25 \pm 1.26$ & $2.76 \pm 1.01$ & $2.45 \pm .95$ & 0.000 \\
\hline Relationships with other soldiers & $2.62 \pm 1.11$ & $2.47 \pm 1.03$ & $2.25 \pm .98$ & $2.09 \pm .83$ & 0.000 \\
\hline Satisfaction with service location & $3.60 \pm 1.22$ & $3.63 \pm 1.17$ & $3.06 \pm 1.08$ & $2.75 \pm 1.12$ & 0.000 \\
\hline Satisfaction with the barracks & $3.93 \pm 1.17$ & $3.73 \pm 1.09$ & $3.36 \pm 1.06$ & $3.16 \pm 1.17$ & 0.000 \\
\hline Loneliness in military service & $3.70 \pm 1.29$ & $3.69 \pm 1.27$ & $3.16 \pm 1.12$ & $2.88 \pm 1.25$ & 0.000 \\
\hline Shift work satisfaction & $4.20 \pm 1.10$ & $4.13 \pm 1.02$ & $3.55 \pm 1.16$ & $3.45 \pm 1.18$ & 0.000 \\
\hline Average number of drug abusing friends in military service & $4.13 \pm 5.09$ & $7.56 \pm 27.68$ & $1.34 \pm 2.13$ & $0.80 \pm 4.03$ & 0.014 \\
\hline
\end{tabular}

${ }^{\mathrm{a}}$ Values are expressed as Mean $\pm \mathrm{SD}$.

Table 4. Multivariate Analysis Result of Military Factors Related to Drug Abuse Change

\begin{tabular}{|c|c|c|c|}
\hline Variable & OR & SE.OR & P Value \\
\hline Level of satisfaction with service location & 0.83 & 0.11 & 0.040 \\
\hline Relationships with other soldiers & 0.71 & 0.14 & 0.031 \\
\hline Relationship with commander & 0.79 & 0.14 & 0.001 \\
\hline Time of additional service & 1.15 & 0.05 & 0.002 \\
\hline
\end{tabular}

Abbreviations: OR, Odds ratio; SE.OR, Standard error of OR.

of the justifications of worsening drug abuse is high peripheral stress and non-compatibility in these soldiers.

According to our findings, we can control some predictors of drug abuse, such as time of additional service. This means that if commanders in the military want to punish the soldiers, it is better to avoid this approach. In addition, if commanders behave better with the soldiers, they can help them to solve their problems rather than turning to drugs.

\section{Acknowledgments}

We gratefully acknowledge the participants and all individuals who supported us in this research.

\section{Footnotes}

Authors' Contribution: Ali Reza Mehrazmay, Zahra Najafimanesh and Mahmood Salesi analysed the data and discussed the findings; Ali Reza Karambakhsh designed the study,collected the data and wrote the manuscript draft; Khodabakhsh Ahmadi critically revised the final article. 
Funding/Support: This study was supported by the behavioral sciences research center of Baqiyatallah University of Medical Sciences).

\section{References}

1. Ohiri K. HIV/AIDS prevention among injection drug users: Learning from harm reduction in Iran. Iran: HIV Prevention Consultation; 2006.

2. Iran drug control headquarter portal .2013. Last position of addiction and substance use prevalence rates in the country; .

3. Razzaghi EM, Movaghar AR, Green TC, Khoshnood K. Profiles of risk: a qualitative study of injecting drug users in Tehran, Iran. Harm Reduct J. 2006;3:12. doi:10.1186/1477-7517-3-12. [PubMed: 16545137].

4. Tavolacci MP, Ladner J, Grigioni S, Richard L, Villet H, Dechelotte P. Prevalence and association of perceived stress, substance use and behavioral addictions: a cross-sectional study among university students in France, 2009-2011. BMC Public Health. 2013;13:724. doi: 10.1186/1471-2458-13-724. [PubMed: 23919651].

5. Sinha R. Chronic stress, drug use, and vulnerability to addiction. Ann NYAcad Sci. 2008;1141:105-30. doi: 10.1196/annals.1441.030. [PubMed 18991954].
6. Kao TC, Schneider SJ, Hoffman KJ. Co-occurrence of alcohol, smokeless tobacco, cigarette, and illicit drug use by lower ranking military personnel. Addict Behav. 2000;25(2):253-62. [PubMed: 10795949].

7. Curtis AJ. Health psychology. Psychology Press; 2000.

8. Fathi Ashtiani A, Sajadechi A. Psychological assessment of the soldiers of material and logistics command of a military unit.J Mil Med. 2005;7(2):153-9.

9. Knight K, Simpson DD, Morey JT. An evaluation of the TCU Drug Screen. Washington, DC: National Institute of JusticeOffice of Justice ProgramsUS Department of Justice; 2002.

10. Makela K. Studies of the reliability and validity of the Addiction Severity Index. Addiction. 2004;99(4):398-410. doi: 10.1111/j.13600443.2003.00665.x. [PubMed: 15049734].

11. Sinha R. How does stress increase risk of drug abuse and relapse?. Psychopharmacology (Berl). 2001;158(4):343-59. doi: 10.1007/s002130100917. [PubMed: 11797055].

12. Kaplan HI, Sadock BJ. Comprehensive textbook of psychiatry, Vols. 1 \& 2. Williams \& Wilkins Co; 1989.

13. Lewis D. In: Handbook on Drug Abuse Prevention. Douglas Z, Robert Holman C, editors. New York: Prentice Hall College Div; 1995. Colleague student. 